\title{
Prevalence of Psychiatric Disorders in Patients Referring to a Psychiatric Clinic in Lorestan Province, West of Iran
}

\author{
Hedayat Nazari (iD ${ }^{1}$, Mandana Saki (D) ${ }^{1,}{ }^{*}$, Sajad Yarahmadi (id ${ }^{1,{ }^{* *}}$ and Zoherh Mohammadi ${ }^{2}$ \\ ${ }^{1}$ Social Determinants of Health Research Center, Lorestan University of Medical Sciences, Khorramabad, Iran \\ ${ }^{2}$ Student Research Committee, Lorestan University of Medical Sciences, Khorramabad, Iran \\ "Corresponding author: Social Determinants of Health Research Center, Lorestan University of Medical Sciences, Khorramabad, Iran. Email: mandana_saki@yahoo.com \\ Corresponding author: Department of Critical Care of Nursing, School of Nursing and Midwifery, Lorestan University of Medical Sciences, Khorramabad, Iran. Email: \\ s.yarahmadiooo@gmail.com
}

Received 2020 October 11; Accepted 2020 October 27.

\begin{abstract}
Background: Psychiatric disorders are common and impose a huge burden globally. The study aimed to examine the prevalence of psychiatric disorders in patients referring to a psychiatric clinic in Lorestan.

Objectives: This study aimed to investigate the prevalence of psychiatric disorders in patients referring to a psychiatric clinic in Lorestan province

Methods: A cross-sectional study was conducted with all people aged 18 years or older. Participants were selected by a convenience sampling method. Diagnostic interviews based on DSM-5 were held for 750 patients who were administered between January and June 2018. The collected data were analyzed by SPSS version 22 using absolute frequency, relative frequency, mean, and chi-square test.

Results: Women included 53\% of the study sample. The most prevalent psychiatric disorders were anxiety (35.3\%) and mood disorders (31.5\%). Depression was the most prevalent mood disorder (63.6\%), followed by generalized anxiety disorder (60\%). The prevalence of psychiatric disorders was higher in people aged 21-30 (28.5\%), the illiterate or primary education group (52.4\%), housekeepers (29.5\%), and married ones (51.8\%).

Conclusions: The majority of the patients referring to the psychiatric clinic suffered from mood and anxiety disorders. Therefore, public health authorities of the province need to take steps to warrant necessary measures, including mental health promotion policies, to improve the mental health status and prevent anxiety and mood disorders.
\end{abstract}

Keywords: DSM-5, Interview, Mental Disorders, Psychiatric Disorder

\section{Background}

Iran is located in the Middle East with a population of more than 79.92 million people, including 39.42 million females and 40.49 million males. Iran is ranked 18th in the world in terms of population (1) In the last few decades, the country has undergone rapid demographic, economic, and social changes. Also, the population growth rate in Iran has decreased, which has caused a change in the age structure. The age group of 20-29 years has become the main age group of Iranian people (2).

According to the World Health Organization (WHO), in the coming decades, we will see changes in the epidemiological patterns of global diseases, and psychiatric disorders will become more prevalent (3). The WHO estimates that one in four families will have at least one member with a psychiatric disorder, and this will impose the most global burden of disease (4). Psychiatric and common dis- orders impose a huge burden globally, and global burden disorders state an estimated $28.62 \%$ of the total disabilityadjusted life years in 2013 in the world (5).

Comprehensive studies on the epidemiological status of psychiatric disorders in Iran have been conducted from 1999 to 2015. In the first national study of psychiatric disorders in Iran conducted by Noorbala et al., 21\% of the population over the age of 15 had a psychiatric disorder (1). The results of a similar study showed that the prevalence of psychiatric disorders was $23 \%$ (6). The latest study, conducted in 2015 , showed that a total of $23.4 \%$ of the subjects were suspected of psychiatric disorders; in this study, the prevalence of mental illnesses varied in various provinces (7). In a review study published in 2020 , the prevalence of psychiatric disorders in Iran was 31\% in studies using screening tools and $21 \%$ in studies conducted with clinical interviews (8). Also, a review of studies on the prevalence of mental ill- 
nesses showed that the prevalence rate varies across Iran (1, 9).

The prevalence of psychiatric disorders in some parts of Iran is as follows: $21.5 \%$ in Tehran, $23.8 \%$ in Gilan, $23.7 \%$ in Kashan, 19.9\% in Isfahan, 17\% in Rudsar, 16.6\% in Gonabad, $14 \%$ in Semnan, and $12.5 \%$ in Meibod (10). Also, according to previous studies, the prevalence of various types of psychiatric disorders is different (10-12). Epidemiologic studies in the field of psychiatric disorders play a vital role in determining the mental health of the community and subsequent policy-making and planning (13). Effective planning to provide mental health services in Iran needs fundamental demographic information, the prevalence by the type of disease, and the survey of the country's health status (3). To make policies and strategies for the control and prevention of psychiatric disorders, the prevalence of various types of diseases in each specific community should be determined (2). For instance, data on the prevalence and incidence of psychiatric disorders assist in the identification of those needing treatment and aid in facilitating access (5).

There is little information about the possible impact of social, economic, and health developments on people's mental health status. Addressing the health needs of people requires current information in diverse areas (6). The results of a study on the mental health status of people over the age of 15 in Lorestan province showed that more than one-third of the subjects were suspected of psychiatric disorders. Also, the prevalence of psychiatric disorders increased from $19.7 \%$ in 1999 to $36.3 \%$ in 2015. The prevalence of patients suspected of anxiety and somatization symptoms was higher than the prevalence of depression and anti-social disorders (12). Similar results were obtained in other regions of Iran $(12,14,15)$. However, with social alterations in recent years, there is a potential change in the structure of society in terms of mental health. Population-based studies of psychiatric disease prevalence in Lorestan are rare, equally considering the prevalence of psychiatric disorders in numerous regions of Iran.

\section{Objectives}

This study aimed to investigate the prevalence of psychiatric disorders in patients referring to a psychiatric clinic in Lorestan province.

\section{Methods}

A cross-sectional study was conducted on all people aged 18 years or older. The survey was conducted from January to June 2018. The study population included people referring to the Psychiatric Disorders Clinic of Lorestan
University of Medical Sciences, Khorramabad, Iran. Participants were selected by a convenience sampling method. A total of 750 individuals participated in the examinations. Subjects were referred for clinical interviews by two psychiatrists based on the Diagnostic and Statistical Manual of Mental Disorders (DSM-5) checklist. The clinical interview checklist was provided by two psychiatrists based on the DSM-5 criteria and assessed simultaneously by two psychiatrists to agree upon the same diagnosis. The Kappa coefficient was 0.87. This tool included 149 symptoms of psychiatric disorders, including anxiety, mood disorder, psychosomatic disorders, psychotic disorders, mental retardation, epilepsy, and psychiatric disorders caused by organs (15).

In addition, a questionnaire was designed and used to collect basic and demographic information. The items of this questionnaire included gender, age, education, occupation, marital status, history of drug addiction, and history of physical or mental disorders in the family. The answers to this semi-structured questionnaire were collected as self-report. The average time for answering the questions was about 45 minutes. SPSS version 22 was used for data analysis. Absolute frequency, relative frequency, mean, and chi-square test were utilized to report the data. Before completing questionnaires, participants provided their informed consent, and all information remained confidential. The study was approved by the Ethics Committee of Lorestan University of Medical Sciences.

\section{Results}

A total of 750 individuals were invited to participate in this study. The participants had a mean age of $45.0 \pm 14.4$ years. Women included $53 \%$ of the study sample. Table 1 illustrates the participants' demographic information. Psychiatric disorders were most frequent at the ages of 21-30 years and among people with illiterate or primary education (52.4\%). Housekeepers showed a high prevalence of psychiatric disorders (29.5\%) (Table 2). The most prevalent psychiatric disorders were anxiety (35.3\%) and mood disorders (31.5\%) (Table 3). The most prevalent anxiety disorder was generalized anxiety disorder (60\%) (Table 4 ).

\section{Discussion}

This is the first study conducted by full, structured psychiatric interviews with a representative sample of patients referring to a psychiatric clinic in Lorestan. The results showed anxiety (35.3\%) and mood disorders (31.5\%) were the most common psychiatric disorders. The results of this study confirm the findings of prior epidemiological studies in various respects (12). This study was closely 


\begin{tabular}{|c|c|}
\hline Variable & No $(\%)$ \\
\hline \multicolumn{2}{|l|}{ Age } \\
\hline $20 \geq$ & $125(16.7)$ \\
\hline $21-30$ & $214(28.5)$ \\
\hline $31-40$ & $212(28.3)$ \\
\hline $41-50$ & $120(16)$ \\
\hline $50 \leq$ & $79(10.5)$ \\
\hline \multicolumn{2}{|l|}{ Gender } \\
\hline Male & $353(47)$ \\
\hline Female & $397(53)$ \\
\hline \multicolumn{2}{|l|}{ Education } \\
\hline Illiterate or Primary & $393(52.4)$ \\
\hline Diploma & $202(27)$ \\
\hline Higher than diploma & $155(20.6)$ \\
\hline \multicolumn{2}{|l|}{ Occupation } \\
\hline Student & $138(18.4)$ \\
\hline Worker & $88(11.7)$ \\
\hline Self-employed & $147(19.6)$ \\
\hline Unemployed & $150(20)$ \\
\hline Housekeeper & $221(29.5)$ \\
\hline Retired & $6(0.8)$ \\
\hline \multicolumn{2}{|l|}{ Marital status } \\
\hline Single & $305(40.7)$ \\
\hline Married & $389(51.8)$ \\
\hline Widow & $41(5.5)$ \\
\hline Divorced & $15(2)$ \\
\hline \multicolumn{2}{|l|}{ Drug addiction } \\
\hline Yes & $125(16.6)$ \\
\hline No & $625(83.4)$ \\
\hline \multicolumn{2}{|c|}{ Family history of psychiatric disorders } \\
\hline Yes & $209(27.8)$ \\
\hline No & $541(72.2)$ \\
\hline
\end{tabular}

in agreement with the studies by Noorbala in Tehran (16), Ahmadvand in Kashan (15), Preville (17) in Canada, and Simsek in Turkey (18). The results of another study confirmed the high prevalence of anxiety disorders and mood disorders in Iran. Also, the results showed an increasing rate of psychological distress, including depression, in recent years (19). We showed that major depression and generalized anxiety disorder were the most common anxiety and mood disorders, and autism and narcolepsy were the least frequent disorders in Lorestan.
The results showed that most studied subjects were women and the prevalence of psychiatric disorders was higher in females. A review of studies conducted in the world and Iran confirms the results of this study that women are more prone to psychiatric disorders than men. The high prevalence of psychiatric disorders in women compared to men can be due to gender roles, biological factors, environmental factors, job stress, limitation of satisfaction, and lack of social participation in Iran's current population (12, 20, 21). Furthermore, most females are bound to their social roles as housewives; even when a woman works outside the home, she remains a housewife.

Consistent with other studies, the results of this study showed that psychiatric disorders were more common in housewives and unemployed men than in employed men and women $(1,9,15)$. The probable causes of this problem are low income, unemployment stress, restrictions on social interactions, lower chance of marriage, and reducing diversity in the lives of housewives and unemployed ones. The results of this study showed that the prevalence of psychiatric disorders was higher in married people than in single individuals.

Data in this investigation showed that the prevalence of psychiatric disorders was higher in married ones than in single ones. These results are similar to the results of other studies conducted in Iran $(2,15)$. Most studies in the world show that the prevalence of psychiatric disorders is higher in single people than in married individuals (9). The higher prevalence of psychiatric disorders in married people in Iran can be due to marital problems and sexual dysfunction (22). Also, financial problems are much more for married couples than for single people.

In this study, illiterate and primary-educated people (52.4\%) showed a higher prevalence of psychiatric disorders, while people with an academic education (20.6\%) had a lower prevalence; these results are similar to the results of other studies $(2,15)$. Social and cultural limitations and the inability to use the correct mechanism in the face of stress are the reasons for the higher prevalence of psychiatric disorders in people with low education. The lowest incidence of psychiatric disorders was among people with postgraduate degrees, which confirms the findings of most studies conducted in Iran (20).

Despite some improvements in recent years, mental health services have not yet been optimally developed in Lorestan, and there are not many qualified mental health professionals in this province. We need rapid responses to the problem by taking new actions in mental health approaches, programs, organizations, new consultation centers, mental therapeutic services, and support in this region. Considering the high prevalence of anxiety and mood disorders relative to other diseases, the pub- 


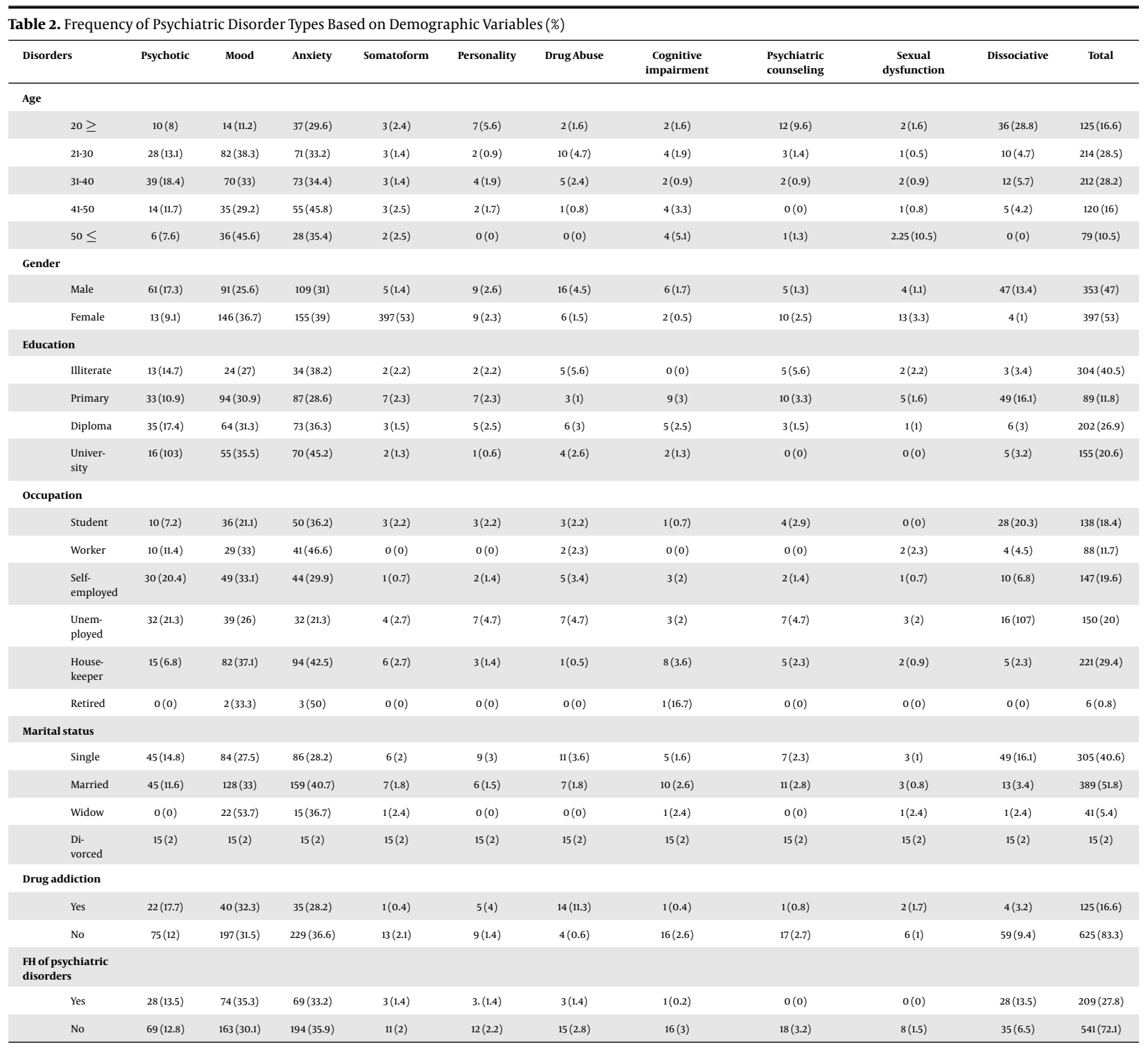

lic health authorities of the province need to warrant necessary measures including mental health promotion policies to improve mental health status and propose ways to develop stressful factors and improve the quality of life. Women, unemployed people, housekeepers, and people with lower education are at a higher risk of psychiatric disorders. The establishment of centers for assessment and diagnosis of high-risk groups and a referral system to counseling and psychiatric clinics is essential.

In conclusion, the majority of the patients referring to the psychiatric clinic suffered from mood and anxiety disorders. Therefore, the public health authorities of the province need to take steps to warrant necessary measures, including mental health promotion policies, to improve the mental health status and prevent anxiety and mood disorders.

\section{Footnotes}

Authors' Contribution: Study concept and design: H.N, Acquisition of data: Z.M, Analysis, and interpretation of data: S.Y, Drafting of the manuscript: S.Y, Critical revision of the manuscript for important intellectual content: M.S, Statistical analysis: Z.M Administrative, technical, and material support: H.N, Study supervision: H.N.

Conflict of Interests: The authors declare that they have no competing interests. 


\begin{tabular}{|c|c|}
\hline Psychiatric Disorders & No(\%) \\
\hline Psychotic & $98(13)$ \\
\hline Mood & $236(31.5)$ \\
\hline Anxiety & $264(35.3)$ \\
\hline Somatoform & $14(1.8)$ \\
\hline Personality & $15(2)$ \\
\hline Drug abuse & $18(2.5)$ \\
\hline Cognitive impairment & $16(2.2)$ \\
\hline Psychiatric counseling & $18(2.5)$ \\
\hline Sexual dysfunction & $8(0.6)$ \\
\hline Dissociative disorders & $63(8.5)$ \\
\hline Variable & No(\%) \\
\hline \multicolumn{2}{|l|}{ Psychotic disorders } \\
\hline Schizophrenia & $20(20.4)$ \\
\hline Psychotic disorder & $78(79.6)$ \\
\hline \multicolumn{2}{|l|}{ Mood Disorders } \\
\hline Depression & $150(63.6)$ \\
\hline Bipolar & $86(36.4)$ \\
\hline \multicolumn{2}{|l|}{ Anxiety disorders } \\
\hline Obsessive-compulsive disorder & $53(20.1)$ \\
\hline Generalized anxiety disorder & $160(60)$ \\
\hline Post-traumatic stress disorder & $26(9.8)$ \\
\hline Panic disorder & $25(9.5)$ \\
\hline \multicolumn{2}{|l|}{ Dissociative disorders } \\
\hline Autism & $5(8)$ \\
\hline Tic & $13(20.6)$ \\
\hline Narcolepsy & $6(9.5)$ \\
\hline Mentally retarded & $12(19)$ \\
\hline ADHD & $27(43)$ \\
\hline
\end{tabular}

Ethical Approval: The study was approved by the Ethics Committee of Lorestan University of Medical Sciences.

Funding/Support: The authors declare that they had no financial source.

Informed Consent: Before completing questionnaires, participants provided their informed consent and all information remained confidential.

\section{References}

1. Noorbala AA, Bagheri Yazdi SA, Yasamy MT, Mohammad K. Mental health survey of the adult population in Iran. Br J Psychiatry.
2004;184:70-3. doi: 10.1192/bjp.184.1.70. [PubMed: 14702230].

2. Mohammadi MR, Davidian H, Noorbala AA, Malekafzali H, Naghavi HR, Pouretemad HR, et al. An epidemiological survey of psychiatric disorders in Iran. Clin Pract Epidemiol Ment Health. 2005;1:16. doi: 10.1186/1745-0179-1-16. [PubMed: 16185355]. [PubMed Central: PMC1253522].

3. Fombonne E, Marcin C, Manero AC, Bruno R, Diaz C, Villalobos M, et al. Prevalence of Autism Spectrum Disorders in Guanajuato, Mexico: The Leon survey. J Autism Dev Disord. 2016;46(5):1669-85. doi: 10.1007/s10803-016-2696-6. [PubMed: 26797939].

4. Lopez AD, Mathers CD, Ezzati M, Jamison DT, Murray CJ. Global burden of disease and risk factors. World Bank Group; 2006. doi: 10.1596/978-08213-6262-4.

5. Murray CJ, Barber RM, Foreman KJ, Ozgoren AA, Abd-Allah F, Abera SF, et al. Global, regional, and national disability-adjusted life years (DALYs) for 306 diseases and injuries and healthy life expectancy (HALE) for 188 countries, 1990-2013: quantifying the epidemiological transition. The Lancet. 2015;386(10009):2145-91.

6. Sharifi V, Amin-Esmaeili M, Hajebi A, Motevalian A, Radgoodarzi R, Hefazi M, et al. Twelve-month prevalence and correlates of psychiatric disorders in Iran: the Iranian Mental Health Survey, 2011. Archives of Iranian medicine. 2015;18(2):0.

7. Noorbala AA, Faghihzadeh S, Kamali K, Yazdi SAB, Hajebi A, Mousavi MT, et al. Mental health survey of the Iranian adult population in 2015. Archives of Iranian medicine. 2017;20(3):0.

8. Fatahi A, Doosti-Irani A, Cheraghi Z. Prevalence and Incidence of Metabolic Syndrome in Iran: A Systematic Review and Meta-Analysis. Int J Prev Med. 2020;11:64. doi: 10.4103/ijpvm.IJPVM_489_18. [PubMed: 32577194]. [PubMed Central: PMC7297433].

9. Noorbala AA, Faghihzadeh S, Kamali K, Bagheri Yazdi SA, Hajebi A, Mousavi MT, et al. Mental Health Survey of the Iranian Adult Population in 2015. Arch Iran Med. 2017;20(3):128-34. [PubMed: 28287805].

10. Noorbala AA, Bagheri Yazdi SA, Faghihzadeh S, Kamali K, Faghihzadeh E, Hajebi A, et al. A Survey on Mental Health Status of Adult Population Aged 15 and above in the Province of Markazi, Iran. Arch Iran Med. 2017;20(11 Suppl. 1):S79-82. [PubMed: 29481135].

11. Noorbala AA, Bagheri Yazdi SA, Faghihzadeh S, Kamali K, Faghihzadeh E, Hajebi A, et al. A Survey on Mental Health Status of Adult Population Aged 15 and above in the Province of Khouzestan, Iran. Arch Iran Med. 2017;20(11 Suppl. 1):S63-6. [PubMed: 29481131].

12. Noorbala AA, Bagheri Yazdi SA, Faghihzadeh S, Kamali K, Faghihzadeh E, Hajebi A, et al. A Survey on Mental Health Status of Adult Population Aged 15 and above in the Province of Lorestan, Iran. Arch Iran Med. 2017;20(11 Suppl. 1):S75-8. [PubMed: 29481134].

13. Mirza I, Jenkins R. Risk factors, prevalence, and treatment of anxiety and depressive disorders in Pakistan: systematic review. BMJ. 2004;328(7443):794. doi: 10.1136/bmj.328.7443.794. [PubMed: 15070634]. [PubMed Central: PMC383372].

14. Noorbala AA, Bagheri Yazdi SA, Faghihzadeh S, Kamali K, Faghihzadeh E, Hajebi A, et al. A Survey on Mental Health Status of Adult Population Aged 15 and above in the Province of Razavi Khorasan, Iran. Arch Iran Med. 2017;20(11 Suppl.1):S99-S102. [PubMed: 29481140].

15. Ahmadvand A, Sepehrmanesh Z, Sadat-Ghoreishi F, Afshinmajd S. Prevalence of psychiatric disorders in the general population of Kashan, Iran. Archives of Iranian medicine. 2012;15(4):0.

16. Noorbala AA, Yazdi SAB, Faghihzadeh S, Kamali K, Faghihzadeh E, Hajebi A, et al. A survey on mental health Status of adult population aged 15 and above in the Province of Tehran, Iran. Archives of Iranian Medicine. 2017;20(13):S115-8.

17. Preville M, Boyer R, Grenier S, Dube M, Voyer P, Punti R, et al. The epidemiology of psychiatric disorders in Quebec's older adult population. Can J Psychiatry. 2008;53(12):822-32. doi: 10.1177/070674370805301208. [PubMed:19087480].

18. Simsek Z, Ak D, Altindag A, Gunes M. Prevalence and predictors of mental disorders among women in Sanliurfa, Southeastern Turkey. 
J Public Health (Oxf). 2008;30(4):487-93. doi: 10.1093/pubmed/fdn025. [PubMed: 18400696].

19. Noorbala AA, BAGHERI YAZDISA, Hafezi M. Trends in Change of Mental Health Status in the Population between 1998 and 2007. ARCHIVES OF IRANIAN MEDICINE. 2012;15(4):201-4.

20. Noorbala A, BAGHERI YAZDI SA, VAEZ MAHDAVI MR, ASADI LARI MOHSEN, Faghihzadeh S, Mohammad K, et al. Mental health changes in Tehran during a 12-year period: Comparing national health and disease survey in 1999 and equality project in 2011. DANESHVAR MEDICINE. 2014;22(113):37.
21. Kessler RC, Aguilar-Gaxiola S, Alonso J, Chatterji S, Lee S, Ormel J, et al. The global burden of mental disorders: an update from the WHO World Mental Health (WMH) surveys. Epidemiol Psichiatr Soc. 2009;18(1):23-33. doi: 10.1017/s1121189x00001421. [PubMed: 19378696]. [PubMed Central: PMC3039289].

22. Khazaei M, Rostami R, Zaryabi A. The Relationship Between Sexual Dysfunctions and Marital Satisfaction in Iranian Married Students. Procedia - Social and Behavioral Sciences. 2011;30:783-5. doi: 10.1016/j.sbspro.2011.10.152. 